\title{
The ent-15 $\alpha$-Acetoxykaur-16-en-19-oic Acid Relaxes Rat Artery Mesenteric Superior via Endothelium-Dependent and Endothelium-Independent Mechanisms
}

\author{
Êrica Adélia Nogueira Ribeiro, ${ }^{1}$ Edla de Azevedo Herculano, ${ }^{1}$ \\ Cintia Danieli Ferreira da Costa, ${ }^{1}$ Fabiola Fialho Furtado, ${ }^{2}$ \\ Emídio Vasconcelos Leitão da-Cunha, ${ }^{2,3}$ José Maria Barbosa-Filho, ${ }^{2}$ \\ Marcelo Sobral da Silva, ${ }^{2}$ and Isac Almeida de Medeiros ${ }^{2}$ \\ ${ }^{1}$ Escola de Enfermagem e Farmácia, Universidade Federal de Alagoas, Cidade Universitária, Tabuleiro dos Martins, \\ 57072-970 Maceió, AL, Brazil \\ ${ }^{2}$ Laboratório de Tecnologia Farmacêutica, Universidade Federal da Paraíba, P.O. Box 5009, 58051-970 João Pessoa, PB, Brazil \\ ${ }^{3}$ Departamento de Farmácia, CCBS, Universidade Estadual da Paraíba, 58100-000 Campina Grande, PB, Brazil \\ Correspondence should be addressed to Êurica Adélia Nogueira Ribeiro, euricanogueira@gmail.com
}

Received 21 August 2012; Revised 7 November 2012; Accepted 13 November 2012

Academic Editor: Jairo Kenupp Bastos

Copyright () 2012 Êurica Adélia Nogueira Ribeiro et al. This is an open access article distributed under the Creative Commons Attribution License, which permits unrestricted use, distribution, and reproduction in any medium, provided the original work is properly cited.

\begin{abstract}
The objective of the study was to investigate the mechanism of the relaxant activity of the ent-15 $\alpha$-acetoxykaur-16-en-19-oic acid (KA-acetoxy). In rat mesenteric artery rings, KA-acetoxy induced a concentration-dependent relaxation in vessels precontracted with phenylephrine. In the absence of endothelium, the vasorelaxation was significantly shifted to the right without reduction of the maximum effect. Endothelium-dependent relaxation was significantly attenuated by pretreatment with L-NAME, an inhibitor of the NO-synthase (NOS), indomethacin, an inhibitor of the cyclooxygenase, L-NAME + indomethacin, atropine, a nonselective antagonist of the muscarinic receptors, ODQ, selective inhibitor of the guanylyl cyclase enzyme, or hydroxocobalamin, a nitric oxide scavenger. The relaxation was completely reversed in the presence of L-NAME $+1 \mathrm{mM} \mathrm{L}$-arginine or L-arginine, an NO precursor. Diterpene-induced relaxation was not affected by TEA, a nonselective inhibitor of $\mathrm{K}+$ channels. The KAacetoxy antagonized $\mathrm{CaCl}_{2}$-induced contractions in a concentration-dependent manner and also inhibited an $80 \mathrm{mM} \mathrm{KCl}$-induced contraction. The KA-acetoxy did not interfere with $\mathrm{Ca}^{2+}$ release from intracellular stores. The vasorelaxant induced by KA-acetoxy seems to involve the inhibition of the $\mathrm{Ca}^{2+}$ influx and also, at least in part, by endothelial muscarinic receptors activation, $\mathrm{NO}$ and $\mathrm{PGI}_{2}$ release.
\end{abstract}

\section{Introduction}

The use of alternative therapies, herbs, and supplements occurs at a very high rate among patients with cardiovascular disease including hypertension [1]. Hypertensive disease is a major public health problem affecting 1 billion individuals, and approximately 7.1 million deaths per year may be attributable to hypertension [2]. The treatment of this disease with plant derivatives is well reported in the literature [3].

Several medicinal plants have been largely studied and their therapeutic potential has been demonstrated in animals, aiming to provide a scientific basis for the therapeutic applications. In this context, we highlight the impact and importance of medicinal plants containing diterpenoids and their action antihypertensive. For example, Croton zambesicus is used in traditional medicine in Africa to treat hypertension. The diterpenes isolated from the extract of plant induced vascular relaxation and antihypertensive effect $[4,5]$. The Marrubium vulgare is a plant used as an antihypertensive agent. The crude extract decreases systolic blood pressure in spontaneously hypertensive rats [6].

Guatteria juruensis Diels (Annonaceae) is a large shrub or small tree indigenous to Central and South America. Various species of the genus Guatteria have been used as medicines 
in the treatment of gonorrhea, renal calculi, and pellagra, as well as diuretic [7]. The KA-acetoxy (ent-15 $\alpha$-acetoxykaur16-en-19-oic acid) is a kaurane-type diterpene, isolated from leaves of this plant.

Terpenoids constitute the largest family of natural products $[8,9]$ and are classified by the homologous series of a number of five carbon isoprene units in their structure: hemiterpenes C5 (1 isoprene unit), monoterpenes C10 ( 2 isoprene units), sesquiterpenes C15 (3 isoprene units), diterpenes C20 (4 isoprene units), and triterpenes C30 (6 isoprene units) [10].

Biological assays have shown that the diterpenes exert hypotensive and antihypertensive action. The kaurenoic acid relaxes isolated rat aorta by blocking extracellular $\mathrm{Ca}^{2+}$ influx blocked, activation of NO-cGMP pathway, and the opening of $\mathrm{K}^{+}$channels $[11,12]$. Stevioside, diterpenoid glycoside, produced vasorelaxant and hypotensive effects in rats [13, 14]. The ent-pimara-8(14),15-dien-19-oic acid reduces vascular resistance via the inhibition of extracellular $\mathrm{Ca}^{2+}$ influx and release of endothelium-derived relaxing factors [15]. The diterpene ent-8(14),15-pimaradien-3 $\beta$-ol also induced vascular relaxation [16]. Three other ent-kaurane derivates isolated from Oyedaea verbesinoides (Asteraceae) induced relaxation in aortic rings [17].

Based on this premise, it is evident that the importance of studies characterizes the cardiovascular activities of kauranetype diterpene, because these compounds can be a promising source for the discovery of numerous bioactive molecules and the development of novel antihypertensive agents [3].

In a broad pharmacological screening performed in our laboratory, we observed in isolated mesenteric superior rings of rats that KA-acetoxy produced a relaxant action on smooth muscle. The present study aimed to elucidate the mechanism of this vasorelaxant effect induced by KA-acetoxy in rat isolated mesenteric rings.

\section{Methods}

2.1. Plant Material. The leaves of Guatteria juruensis Diels (Annonaceae) were collected in August 2001 at the Mocambo Reserve, near the city of Belém, State of Pará, Brazil, and identified by the Annonaceae specialist Dr. Jorge Oliveira, from the Museu Paraense Emílio Goldi (MPEG). A voucher specimen (no. 148.677) has been deposited at the Herbarium of MPEG, Belém, Pará, Brazil.

2.2. Procedure for Isolation of KA-Acetoxy. The dried and powdered leaves $(5.230 \mathrm{~g})$ were extracted in a Soxhlet apparatus. The solvents used were first hexane, then chloroform, and finally EtOH. The hexane extract yielded after cooling a white precipitate. This precipitate, after filtration and washing with hot hexane, yielded KA-acetoxy $(5.38 \mathrm{~g})$. KAacetoxy was identified by means of spectroscopic methods, mainly 1D and 2D NMR as ent-15 $\alpha$-acetoxykaur-16-en-19oic acid [18] (Figure 1). In fact just using hot hexane, KAacetoxy was obtained as a pure compound, according with the melting point $\left(\mathrm{mp}=178-180^{\circ} \mathrm{C}\right)$ in comparison with the literature and by means of spectroscopic methods. The

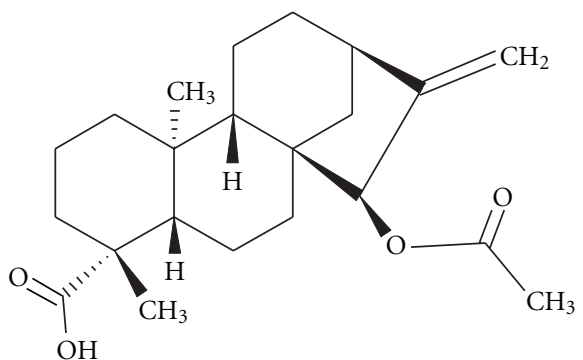

FIgURE 1: Chemical structure of KA-acetoxy.

isolation of KA-acetoxy was previously described by [19] and its structure has been elucidated based on IR, NMR of $1 \mathrm{H}$ - and 13C 1D, and 2D-spectroscopic techniques including DEPT, HETCOR, HMBC, and NOESY.

2.3. Drugs. The following drugs were used: atropine sulfate, acetylcholine hydrochloride (ACh), indomethacin, $\mathrm{N}^{\mathrm{G}}$-nitro L-arginine methyl ester (L-NAME), L-phenylephrine chloride (Phe), L-arginine, ethylene glycol bis( $\beta$-aminoethylether)-N,N, $\mathrm{N}^{\prime}, \mathrm{N}^{\prime}$-tetraacetic acid (EGTA), caffeine, hydroxycobalamin (HDX), tetraethylammonium (TEA), and $1 \mathrm{H}$ $[1,2,3]$ oxadiazolo $[4,3-\alpha]$ quinoxalin-1-one (ODQ) (all from SIGMA). KA-acetoxy was solubilized in a mixture of distilled water cremophor at a concentration of $10 \mathrm{mM}$ and diluted to the desired concentration with distilled water just before use. Indomethacin was dissolved in $0.5 \% \mathrm{w} / \mathrm{v}$ sodium bicarbonate. ODQ was prepared as stock solution dimethyl sulfoxide (DMSO). EGTA was added in the $\mathrm{Ca}^{2+}$-free Tyrode's solution. The other compounds were freely dissolved in distilled water. The final concentration of cremophor and DMSO in the bath never exceeded $0.01 \%$ was without effect when tested in control preparations (data not shown).

2.4. Animals. Male Wistar rats (200-300 g) were used in all experiments. Experimental protocols and procedures were approved by the Laboratório de Tecnologia Farmacêutica Animal Care and Use Committee. Animals were housed under conditions of controlled temperature $\left((25 \pm 1)^{\circ} \mathrm{C}\right)$ and lighting (light on 6:00-18:00 h) and had access to food and tap water ad libitum.

2.5. Tissue Preparation. Rats were killed by stunning and exsanguination. The superior mesenteric artery was removed, cleaned from connective tissue and fat and sectioned in rings $(1-2 \mathrm{~mm})$, which were suspended by cotton threads in organ baths containing $10 \mathrm{~mL}$ of Tyrode's solution (composition in mM: $\mathrm{NaCl}: 158.3: \mathrm{KCl}: 4.0 ; \mathrm{CaCl}_{2}: 2.0 ; \mathrm{MgCl}_{2}$ : 1.05; $\mathrm{NaH}_{2} \mathrm{PO}_{4}: 0.42 ; \mathrm{NaHCO}_{3}: 10.0$; and glucose: 5.6.), gassed with carbogenic mixture $\left(95 \% \mathrm{O}_{2}\right.$ and $\left.5 \% \mathrm{CO}_{2}\right)$, and maintained at $37^{\circ} \mathrm{C}$ for isometric $n$ tension recordings. The stabilization period was of $1 \mathrm{~h}$ under a resting tension of $0.75 \mathrm{~g}$. During this time, the solution was changed each $15 \mathrm{~min}$ to prevent the accumulation of metabolites. The isometric tension was recorded by a force transducer (Gould, Model GM2, USA) coupled to an amplifier recorder (Gould, 
USA). Endothelium was removed by gently rubbing the intimal surface of the vessels. The presence of functional endothelium was assessed by the ability of acetylcholine (ACh) $(10 \mu \mathrm{M})$ to induce more than $80 \%$ relaxation of precontracted vessels with Phe $(10 \mu \mathrm{M})$. The absence of the relaxation to $\mathrm{ACh}$ was taken as evidence that the vessel segments were functionally denuded of endothelium.

\subsection{Effect of KA-Acetoxy on Superior Mesenteric Rings Pre-} contracted with Phe or $\mathrm{K}^{+}$-Depolarizing Solutions $(80 \mathrm{mM}$ $\mathrm{KCl}$ ). In the first set of experiments, the ability of KAacetoxy to cause vascular relaxation was evaluated in both endothelium-intact and endothelium-denuded mesenteric artery rings previously contracted by Phe $(10 \mu \mathrm{M})$. Under the sustained contraction elicited by Phe the vessels were exposed to cumulative concentrations of KA-acetoxy $\left(10^{-6}-1 \mathrm{mM}\right)$.

In the second set of experiments, after the stabilization period, rings without endothelium were precontracted with $\mathrm{KCl} 80 \mathrm{mM}$ on the tonic phase and different concentrations of KA-acetoxy $\left(10^{-6}-1 \mathrm{mM}\right)$ were added cumulatively to organ bath. The extent of relaxation was expressed as the percentage of phenylephrine- or $\mathrm{KCl}$-induced contraction.

\subsection{Verification of the Participation of Endothelium-Derived} Products and Muscarinic Receptors in the Relaxant Effect of KA-Acetoxy. To investigate the possible mechanism(s) responsible for KA-acetoxy induced relaxation, the preparations with endothelium were precontracted with Phe for 30 min after being early incubated with one of the following inhibitors: atropine $(1 \mu \mathrm{M})$, a nonselective antagonist of the muscarinic receptors, L-NAME $(100 \mu \mathrm{M})$, an inhibitor of the NO-synthase (NOS), L-NAME plus L-arginine (1 mM), NOS substrate, L-arginine alone, indomethacin $(10 \mu \mathrm{M})$, an inhibitor of the cyclooxygenase (COX), L-NAME + indomethacin, ODQ $(10 \mu \mathrm{M})$, selective inhibitor of the guanylyl cyclase enzyme, and hydroxocobalamine $(30 \mu \mathrm{M})$, a nitric oxide scaveng, separately.

2.8. Investigation of the Role of $K^{+}$Channels in the KAAcetoxy-Induced Vasorelaxant Response. Phe-induced sustained contractions were obtained in endothelium-intact and endothelium-denuded mesenteric artery rings incubated with tetraethylammonium, a nonselective inhibitor of $\mathrm{K}^{+}$ channels (TEA, $5 \mathrm{mM}$ ), and then concentration-response curves to KA-acetoxy were obtained. The TEA was added 30 minutes before the contractions with Phe.

2.9. Effect of KA-Acetoxy on Contractions Induced by $\mathrm{CaCl}_{2}$. In order to access the effects of KA-acetoxy on voltagegated $\mathrm{Ca}^{2+}$ channels, superior mesenteric artery rings were bathed for $15 \mathrm{~min}$ in $\mathrm{Ca}^{2+}$-free Tyrode's solution, prepared by omitting only $\mathrm{CaCl}_{2}$ and then exposed for an additional $15 \mathrm{~min}$ to a high $\mathrm{K}^{+}(60 \mathrm{mM}) \mathrm{Ca}^{2+}$-free solution. Under this new experimental condition, cumulative concentration response curves to $\mathrm{CaCl}_{2}$ (ranging from $1 \mu \mathrm{M}$ to $10 \mathrm{mM}$ ) were obtained. KA-acetoxy $(3,30,100,300 \mu \mathrm{M}$, or $1 \mathrm{mM})$ was added to the preparations for $30 \mathrm{~min}$, and then a new cumulative concentration-response curve for $\mathrm{CaCl}_{2}$ was determined. The maximal contraction obtained with the control concentration-response curve to $\mathrm{CaCl}_{2}$ was taken as $100 \%$ and all values were calculated as a percentage of the maximal response. Each preparation was exposed to only one diterpene-concentration. All experiments were done using endothelium-denuded superior mesenteric artery rings.

2.10. Effect of KA-Acetoxy on Phenylephrine- and CaffeineInduced Contractions in $\mathrm{Ca}^{2+}$-Free Solution. The effect of KA-acetoxy on phenylephrine- or caffeine-sensitive calcium intracellular stores was assessed by using a protocol described by Sakata and Karaki [20]. The transient contractions were obtained in endothelium denuded rings by $10 \mu \mathrm{M}$ Phe or $20 \mathrm{mM}$ caffeine in $\mathrm{Ca}^{2+}$-free solution before and after incubation with KA-acetoxy $(100 \mu \mathrm{M}, 300 \mu \mathrm{M}$ or $1 \mathrm{mM})$ for $20 \mathrm{~min}$. The results were expressed as percentages of the response induced by Phe or caffeine alone.

2.11. Statistical. In order to study the effect of KA-acetoxy on inducing relaxation, two pharmacological parameters were analysed: the $E_{\max }$ (maximal effect generated by the agonist) and $\mathrm{pD}_{2}\left(-\log E C_{50}\right)$. Results are expressed as means \pm standard error of the mean (SEM). Student's $t$-test and oneway analysis of variance (Anova) using Bonferroni's posttest was used to analyse the data, and results were considered significant when $P<0.05$.

\section{Results}

3.1. Effect of KA-Acetoxy on Superior Mesenteric Rings Precontracted with Phe- or $\mathrm{K}^{+}$-Depolarizing Solutions $(80 \mathrm{mM}$ $\mathrm{KCl}$ ). Table 1 shows that KA-acetoxy completely and in a concentration-dependent manner relaxed the phenylephrine induced contraction in artery segments with intact endothelium. In endothelium-denuded vessels, there was a significant rightward shift in the concentration-response curve to KA-acetoxy no change in $E_{\max }$ as compared to the control. In rings without endothelium precontracted with $\mathrm{K}^{+}$-depolarizing solution $(\mathrm{KCl} 80 \mathrm{mM})$, the concentrationresponse curves for KA-acetoxy was significantly rightward shifted no change in $E_{\max }$ as compared to the phenylephrinecontracted endothelium-denuded vessels $\left(\mathrm{pD}_{2}=3.6 \pm 0.1\right.$ and $E_{\max }=87.9 \pm 4.7 \%$ ).

The magnitude of contraction induced by Phe in rings with and without endothelium functional was 0.42 and $0.44 \mathrm{~g}$, respectively. Similarly, the magnitude of contraction induced by $\mathrm{KCl}$ in rings without endothelium was $0.40 \mathrm{~g}$. There were no significant differences between the magnitudes.

\subsection{Verification of the Participation of Endothelium-Derived} Products and Muscarinic Receptors in the Relaxant Effect of KA-Acetoxy. The incubation with L-NAME $(100 \mu \mathrm{M})$, indomethacin $(10 \mu \mathrm{M})$, or L-NAME $(100 \mu \mathrm{M})$ plus indomethacin $(10 \mu \mathrm{M})$ significantly shifted to the right the concentration-response curves of KA-acetoxy. In the same manner, after soluble guanylyl cyclase inhibition (ODQ $10 \mu \mathrm{M}), \operatorname{HDX}(30 \mu \mathrm{M})$, a nitric oxide scaveng, or muscarinic 
TABle 1: Comparison of $E_{\max }$ and $\mathrm{pD}_{2}$ values of KA-acetoxy against tonic contractions induced by phenylephrine in isolated rat mesenteric rings.

\begin{tabular}{lcc}
\hline $\begin{array}{l}\text { Phenylephrine } 10(\mu \mathrm{M}) \\
\text { (condition) }\end{array}$ & $\begin{array}{c}E_{\max } \\
\text { (percentage of relaxation) }\end{array}$ & $\begin{array}{c}\mathrm{pD}_{2} \\
\text { (value) }\end{array}$ \\
\hline Endothelium intact & $92.8 \pm 3.7$ & $6.0 \pm 0.3$ \\
Endothelium denuded & $95.2 \pm 2.8$ & $4.6 \pm 0.2^{* * *}$ \\
L-NAME $(100 \mu \mathrm{M})$ & $67.3 \pm 4.3^{* * *}$ & $4.1 \pm 0.1^{* * *}$ \\
Indomethacin $(10 \mu \mathrm{M})$ & $61.2 \pm 7.4^{* * *}$ & $4.5 \pm 0.3^{*}$ \\
L-NAME + indomethacin & $66.9 \pm 3.6^{* * *}$ & $4.7 \pm 0.3^{*}$ \\
Atropine $(1 \mu \mathrm{M})$ & $73.6 \pm 6.6^{*}$ & $4.4 \pm 0.2^{* * *}$ \\
ODQ $(10 \mu \mathrm{M})$ & $77.7 \pm 3.6^{*}$ & $4.6 \pm 0.5^{*}$ \\
Hydroxycobalamine $(10 \mu \mathrm{M})$ & $68.1 \pm 6.7^{* *}$ & $4.6 \pm 0.3^{*}$ \\
L-arginine $(1000 \mu \mathrm{M})$ & $91.4 \pm 2.9$ & $5.4 \pm 0.4$ \\
L-NAME $+\mathrm{L}$-arginine & $100 \pm 0$ & $5.3 \pm 0.4$ \\
\hline
\end{tabular}

Values are expressed as means \pm SEM of six experiments. These experiments were performed in mesenteric rings with functional endothelium. ${ }^{*} P<$ $0.05,{ }^{* *} P<0.01$ and ${ }^{* * *} P<0.001$ versus endothelium intact. The data were analysed by one-way Anova followed by the Bonferroni post-test.

blockade (atropine $1 \mu \mathrm{M}$ ) reduced KA-acetoxy-induced relaxation and produced a rightward displacement of the concentration-response curve for the compound. However, L-arginine $(1 \mathrm{mM})$ or L-arginine plus L-NAME $(100 \mu \mathrm{M})$ had not significant effect on KA-acetoxy-induced relaxation (Table 1). The means of magnitude of contraction induced by Phe was $0.47 \pm 0.10 \mathrm{~g}$ after incubation with the inhibitors and/or antagonist. There were no significant differences when compared with the magnitude of contraction induced by Phe in the absence of inhibitors and/or antagonist.

3.3. Investigation of the Role of $\mathrm{K}^{+}$Channels in the KAAcetoxy-Induced Vasorelaxant Response. In endotheliumintact and denuded rings precontracted with Phe $(10 \mu \mathrm{M})$, TEA $(5 \mathrm{mM})$, a nonselective inhibitor of $\mathrm{K}^{+}$channels, was not able to change KA-acetoxy relaxations (Table 2).

3.4. Effect of KA-Acetoxy on Contractions Induced by $\mathrm{CaCl}_{2}$. Under this experimental condition, KA-acetoxy produced a nonparallel and concentration-dependent rightward shift of the $\mathrm{CaCl}_{2}$ concentration-response curve significantly reducing the maximal response as illustrated in Figure 2.

3.5. Effect of KA-Acetoxy on Phenylephrine- and CaffeineInduced Contractions in $\mathrm{Ca}^{2+}$-Free Solution. In mesenteric rings under a $\mathrm{Ca}^{2+}$-free solution, KA-acetoxy not inhibited transient contractions induced by $10 \mu \mathrm{M}$ phenylephrine or by $20 \mathrm{mM}$ caffeine (Figure 3 ).

\section{Discussion}

The present work was performed in order to investigate possible vasodilator effects of the KA-acetoxy in the isolated rat superior mesenteric artery. It was observed that diterpene induced concentration-dependent vasorelaxation in the isolated rat superior mesenteric artery. The results also suggest
TABLE 2: Effect of TEA in the relaxant effect of KA-acetoxy.

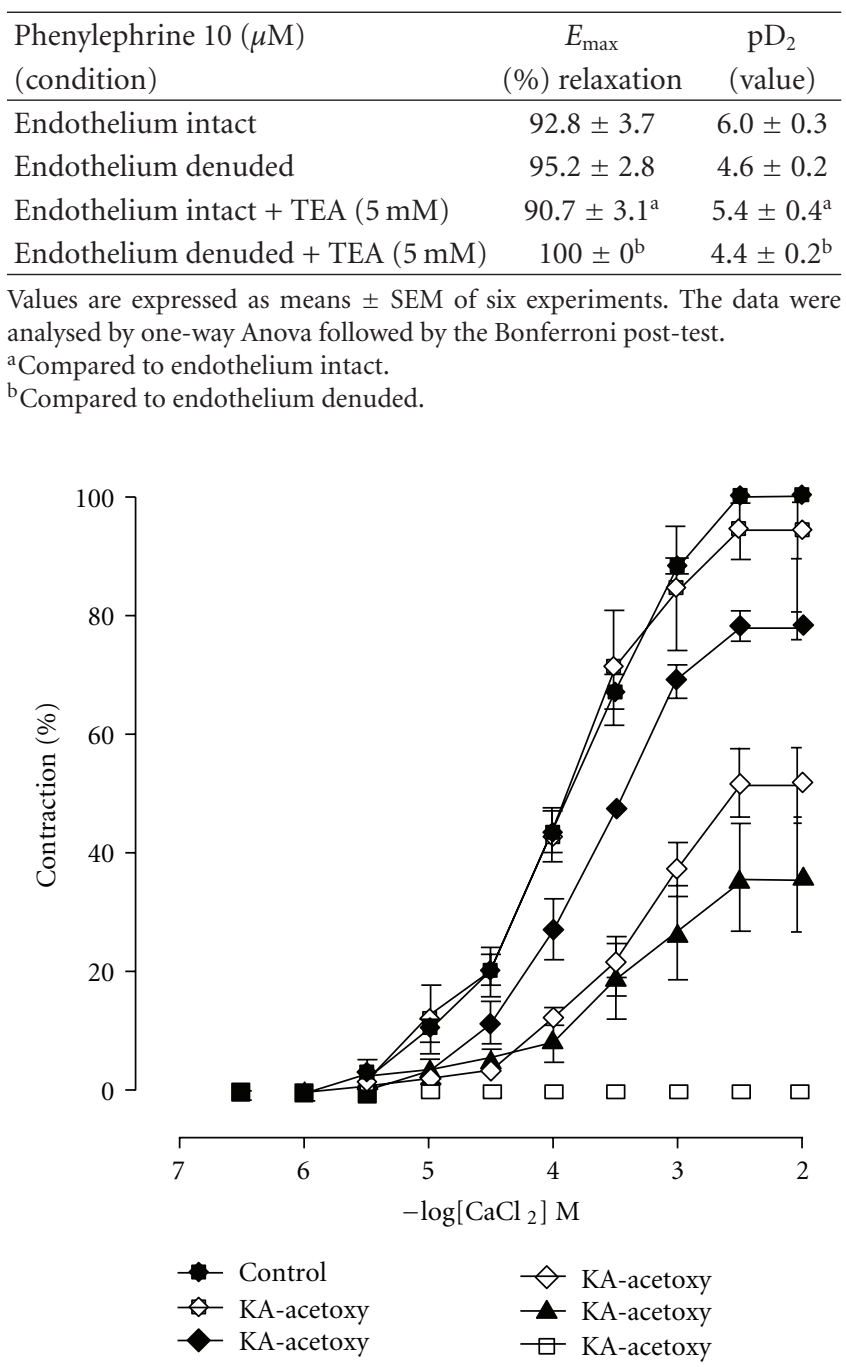

FIgURE 2: Concentration-response curves for $\mathrm{CaCl}_{2}$ before (• control, $n=12$ ) and after the incubation of preparations with KAacetoxy $(\circ 3 \mu \mathrm{M}, n=6),(\diamond 30 \mu \mathrm{M}, n=8),(\diamond 100 \mu \mathrm{M}, n=6)$, $(\Delta 300 \mu \mathrm{M}, n=5)$, or $(\square 1 \mathrm{mM}, n=6)$ in rings of rat mesenteric artery without endothelium. The data were examined using oneway anova followed by the Bonferroni post-test.

that there are two components of the vasodilatory effect: one endothelium dependent and the other endothelium independent.

The vascular endothelium plays an important role in homeostasis by modulating vascular smooth muscle tone and acts as a main target site in hypertension and atherosclerosis. Regulation of vasodilatation by the endothelium is determined by three main components; NO, prostacyclin and endothelium derived hyperpolarizing factor (EDHF). These endothelium-derived relaxing factors diffuse to adjacent smooth muscle cells and cause them relaxation [21,22]. To determine whether the vasodilatory effect could involve the release of $\mathrm{NO}$ or $\mathrm{PGI}_{2}$, we performed experiments with L-NAME, an inhibitor of NO synthase, and indomethacin, a potent nonselective COX inhibitor, separately. In the 


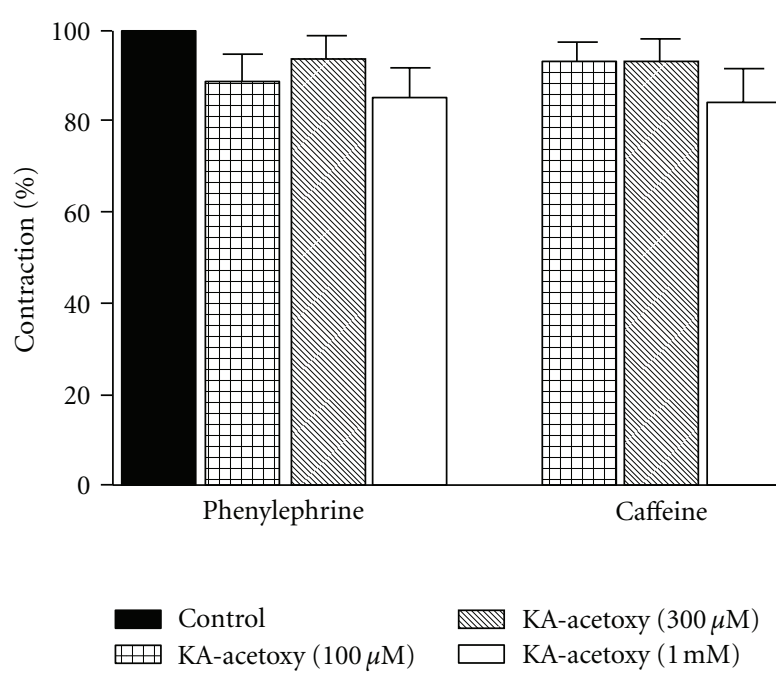

Figure 3: Effects of KA-acetoxy $(100 \mu \mathrm{M}, 300 \mu \mathrm{M}$, or $1 \mathrm{mM})$ on transient contractions induced by phenylephrine $(10 \mu \mathrm{M})$ and caffeine $(20 \mathrm{mM})$ in $\mathrm{Ca}^{2+}$-free Tyrode's solution in isolated rat mesenteric rings without the endothelium. Values are expressed as means \pm SEM of six experiments. The data were analysed by oneway anova followed by the Bonferroni post-test.

presence of L-NAME or indomethacin, the concentrationresponse curves for KA-acetoxy significantly shifted to the right with reduced $E_{\max }$, suggesting the participation of $\mathrm{NO}$ and cyclooxygenase pathways in the vasorelaxant effect of KA-acetoxy.

L-arginine, a NO precursor, antagonized the effect of LNAME, but when added alone it did not affect the relaxations induced by KA-acetoxy. The inability of this NO synthase substrate to increase the relaxation induced by KA-acetoxy may be explained in terms of there being sufficient amounts of L-arginine in the vascular endothelium. The $K_{m}$ values of the enzyme of L-arginine are 1.5 to $2.3 \mu \mathrm{M}$ [23]. Moreover, hydroxocobalamin, a nitric oxide scaveng [24], caused a significant rightward shift of the concentration-response curve for diterpene in endothelium-intact rings, suggesting again that the action of KA-acetoxy is partially associated with the generation of $\mathrm{NO}$ in the vascular endothelium.

In most vascular beds, the stimulation of muscarinic receptors $\left(\mathrm{M}_{3}\right.$ subtype) produces an intense dilation, despite the lack of vascular cholinergic innervation [25]. The muscarinic receptors responsible for relaxation are located on the endothelial cells and their stimulation leads to the release of EDRFs, mainly NO, which diffuses to adjacent smooth muscle cells and causes them to relax [21]. To determine whether KA-acetoxy-induced NO release could be secondary to the stimulation of endothelial $M_{3}$ receptors [26], we performed experiments on intact superior mesenteric artery preparations that were early incubated with atropine. In these preparations, the vasorelaxant effect of KA-acetoxy was attenuated; in other words, the concentration-response curves for KA-acetoxy significantly shifted to the right with reduced $E_{\max }$. These results suggest that diterpene partly could be acting via endothelial muscarinic receptor activation and consequent of participation of cGMP pathway.

It is well known that NO induces vascular smooth muscle relaxation through activation of guanylyl cyclase, leading to the accumulation of cyclic GMP. Relaxation of vascular smooth-muscle by NO-cGMP signaling involves a sequence of steps. NO released activates soluble guanylyl cyclase. This enzyme catalyzes the conversion of GPT to cGMP. cGMPactivaed protein kinase $\mathrm{G}$ inhibits $\mathrm{Ca}^{2+}$ influx, augments $\mathrm{Ca}^{2+}$ sequestration, and decreases the sensitivity of contractile elements to $\mathrm{Ca}^{2+}$ [27]. Therefore, in order to verify the participation of the NO-GMPc pathway in the effects of a KA-acetoxy in the present study, preparations were incubated with ODQ, a soluble guanylyl cyclase inhibitor. Under these conditions, the concentration-response curve to KA-acetoxy was shifted to the right with reduced $E_{\max }$, suggesting that the relaxant response elicited by diterpene involves the NOsGC-GMPc pathway.

EDHF plays little role in vasoactive responses of conduit vessels, it mediates a major component of the response to endothelium-dependent vasodilators in resistance arteries [28-30]. The chemical identity of EDHF is controversial, although epoxyeicosatrienoic acids, the cytochrome P-450 metabolites of arachidonic acid, have been proposed as possible candidate for $\operatorname{EDHF}[31,32]$. As mentioned, the identity of EDHF is controversial and still unknown enzyme responsible for its production. How to investigate the involvement or not of EDHF the vasorelaxant action of KA-acetoxy? Endothelium-dependent relaxation resistance to COX- and NOS-inhibitors was previously considered to be attributed to EDHF [33-35]. To test this hypothesis; we incubated the preparations with L-NAME and indomethacin, simultaneously. Under these conditions, KA-acetoxy-induced vasorelaxation was attenuated, but not abolished. Therefore, we suggest that the mechanism of the vasorelaxant action of the KA-acetoxy involves the participation of $\mathrm{NO}$ and $\mathrm{PGI}_{2}$, as well as probably the participation of EDHF. Nevertheless further experiments are needed to clear up the mechanisms involved.

The vasodilation mediated by membrane hyperpolarization is attributed to a rise in $\mathrm{K}^{+}$permeability. Direct activation of $\mathrm{K}^{+}$channels on arterial smooth muscle cells normally hyperpolarizes the cell membrane and thus inhibits $\mathrm{Ca}^{2+}$ influx through voltage sensitive $\mathrm{Ca}^{2+}$ channels [36]. Also, it is reported in the literature that EDRFs induce vasorelaxation by activating the $\mathrm{K}^{+}$channels [37]. In addition, several natural products have been shown to induce vasorelaxant effects through the activation of $\mathrm{K}^{+}$channels $[38,39]$. Aiming to investigate the involvement of $\mathrm{K}^{+}$channels the vasorelaxant activity elicited by diterpene, the preparations were early incubated with tetraethylammonium, a nonselective $\mathrm{K}^{+}$channel blocker. This condition, the vasorelaxant activity, was not changed, suggesting that $\mathrm{K}^{+}$channels are not involved in the vasorelaxant effect elicited by KA-acetoxy.

The maintenance of smooth muscle contraction depends on $\mathrm{Ca}^{2+}$ influx from the extracellular space through voltageand/or receptor-operated calcium channels (VOCCs andor receptor operated calcium channels, resp.) [40]. It is well known that the contractions to $\alpha_{1}$-adrenoceptor agonists, 
such as phenylephrine, are initiated by $\mathrm{Ca}^{2+}$ release from intracellular stores, which is followed by activation of $\mathrm{Ca}^{2+}$ activated channels causing depolarization of the vascular smooth muscle cell membranes and activation of voltagegated $\mathrm{Ca}^{2+}$ channels [41]. Whereas that high- $\mathrm{K}^{+}$-induced contraction in smooth muscle is mediated by cell membrane depolarization and an increase in calcium influx through VOCCs [42]. In both cases, the major resulting effect is an increase in the intracellular calcium concentration through calcium entry.

Thus, it is proposed that the residual vasorelaxant effect of the diterpene is due to a mechanism independent of endothelium, possibly a blocking activity on the $\mathrm{Ca}^{2+}$ channels. Based on this assumption, we evaluated the effect of KAacetoxy on endothelium-denuded rings precontracted with $\mathrm{K}^{+}$-depolarizing solutions $(\mathrm{KCl} 80 \mathrm{mM})$. KA-acetoxy was capable to inhibit contractility induced by $\mathrm{KCl}(80 \mathrm{mM})$ in endothelium-denuded mesenteric rings. This result suggests that KA-acetoxy could inhibit $\mathrm{Ca}^{2+}$ influx through VOCCs.

In order to strengthen the above hypothesis, KA-acetoxy was tested in the presence of $\mathrm{CaCl}_{2}$-induced contractions in a depolarizing medium without calcium. This protocol was based on the fact that $\mathrm{CaCl}_{2}$-induced contractions are elicited, almost exclusively, through $\mathrm{Ca}^{2+}$ influx, since the depolarization promoted by high concentrations of extracellular $\mathrm{K}^{+}$induces the opening of voltage-dependent $\mathrm{Ca}^{2+}$ channels [43]. Under this experimental condition, KA-acetoxy produced a nonparallel and concentrationdependent rightward shift of the $\mathrm{CaCl}_{2}$ concentrationresponse curve significantly reducing the maximal response.

The release of intracellular stored $\mathrm{Ca}^{2+}$ is mainly regulated by $\mathrm{IP}_{3}$ receptor system $\left(\mathrm{IP}_{3} \mathrm{Rs}\right)$ and ryanodine receptor system (RyRs). The former induces $\mathrm{Ca}^{2+}$ release directly when the receptors are bound to $\mathrm{IP}_{3}$. The later may function through a $\mathrm{Ca}^{2+}$ induced $\mathrm{Ca}^{2+}$ release (CICR) mechanism when the receptors are activated by caffeine [44]. To investigate the involvement of these stores in the vasorelaxant response induced by KA-acetoxy, we performed experiments using rings contracted by phenylephrine or caffeine, in $\mathrm{Ca}^{2+}$ free solution, in the absence and presence of diterpene. Thus, KA-acetoxy not inhibited transient contractions induced by phenylephrine and caffeine, suggesting that the compound does not interfere in the calcium mobilization of calcium intracellular stores.

KA-acetoxy is a closely related derivate with kaurenoic cid (ent-kaur-16-en-19-oic acid). Similarly, KA-acetoxy was able to induce vasorelaxation vascular tissues such as kaurenoic acid. The mechanism involved in the vasorelaxant action has some similarities, such as extracellular $\mathrm{Ca}^{2+}$ influx blocked and activation of NO-cGMP pathway [11]. Like other diterpenes, the KA-acetoxy also induced their vasorelaxant activity by acting on multiple sites of action [11, 45, 46]. The multiple effects described here were not unlikely caused by toxicity of KA-acetoxy on vascular cells. Firstly, the relaxant effect of agent was reproducible. Secondly, the phenylephrine-induced contractile response was totally restored following 60 minutes of KA-acetoxy.

Recently, we observed that KA-acetoxy induced hypotension activity in animals with essential hypertension (Lyon hypertensive rats) (unpublished data). It is well known that small arteries, as the superior mesenteric artery, play an important role in the determination of the peripheral resistance and in the regulation of blood pressure [47]. We can suggest the hypothesis that hypotensive response could be due to a decrease in peripheral vascular resistance caused by a possible vasorelaxation, since KA-acetoxy induced vasorelaxation in superior mesenteric artery rings in normotensive rats. Therefore, the vasorelaxant activity could be used as a potential substance for antihypertensive treatment.

In addition, only substances that inhibit contractions in $\mathrm{KCl}$ test model are worth further examination in a search for naturally occurring calcium-antagonists. In this context, the KA-acetoxy was able to inhibit contractility induced by $\mathrm{KCl}$. In this context, it is possible to suggest that the KAacetoxy could exert antihypertensive action in vivo as other diterpenes $[11,14]$.

In summary, the present study demonstrated that the KA-acetoxy produced a concentration and endotheliumdependent and -independent vasorelaxation in superior mesenteric artery rings. Endothelium-dependent relaxation appears to be due to endothelial muscarinic receptors activation, $\mathrm{NO}$ and $\mathrm{PGI}_{2}$ release, as well as probably the participation of EDHF. Endothelium-independent relaxation KA-acetoxy acts through inhibition of the $\mathrm{Ca}^{2+}$ influx.

\section{Acknowledgments}

Financial support from CNPq-Brazil is acknowledged gratefully. The authors report no conflict of interests. The authors alone are responsible for the content and writing of this paper.

\section{References}

[1] G. A. Mansoor, "Herbs and alternative therapies in the hypertension clinic," American Journal of Hypertension, vol. 14, no. 9 I, pp. 971-975, 2001.

[2] J. C. Prado, E. Kupek, and D. Mion, "Validity of four indirect methods to measure adherence in primary care hypertensives," Journal of Human Hypertension, vol. 21, pp. 309-312, 2007.

[3] C. R. Tirapelli, S. R. Ambrosio, A. M. de Oliveira, and R. C. Tostes, "Hypotensive action of naturally occurring diterpenes: a therapeutic promise for the treatment of hypertension," Fitoterapia, vol. 81, no. 7, pp. 690-702, 2010.

[4] K. Ohashi, T. Bohgaki, T. Matsubara, and H. Shibuya, "Jamu as a Javanese traditionalmedicine in Indonésia," in Proceedings of the Bioresources Diversity, Ethnobiology Development and Sustainability International Centenary Conference, Sydney, Australia, 1991.

[5] K. Ohashi, T. Bohgaki, T. Matsubara, and H. Shibuya, "Chemical structures of two new migrated pimarane-type diterpenes, neoorthosiphols $\mathrm{A}$ and $\mathrm{B}$, and suppressive effects on rat thoracic aorta of chemical constituents isolated from the leaves of Orthosiphon aristatus (Lamiaceae)," Chemical and Pharmaceutical Bulletin, vol. 48, pp. 433-435, 2000.

[6] S. E. Bardai, B. Lyoussi, M. Wibo, and N. Morel, "Pharmacological evidence of hypotensive activity of Marrubium vulgare and Foeniculum vulgare in spontaneously hypertensive rat," 
Clinical and Experimental Hypertension, vol. 23, no. 4, pp. 329343, 2001.

[7] J. F. Morton, Atlas of Medicinal Plants of Middle Americana, Thomas CC, Spriingfield, Ill, USA, 1981.

[8] J. C. Sacchettini and C. D. Poulter, "Creating isoprenoid diversity," Science, vol. 277, no. 5333, pp. 1788-1789, 1997.

[9] P. M. Dewick, "The biosynthesis of $\mathrm{C}_{5}-\mathrm{C}_{25}$ terpenoid compounds," Natural Product Reports, vol. 19, no. 2, pp. 181-222, 2002.

[10] V. S. Dubey, R. Bhalla, and R. Luthra, "An overview of the nonmevalonate pathway for terpenoid biosynthesis in plants," Journal of Biosciences, vol. 28, no. 5, pp. 637-646, 2003.

[11] C. R. Tirapelli, S. R. Ambrosio, F. B. da Costa, S. T. Coutinho, D. C. R. de Oliveira, and A. M. de Oliveira, "Analysis of the mechanisms underlying the vasorelaxant action of kaurenoic acid in the isolated rat aorta," European Journal of Pharmacology, vol. 492, no. 2-3, pp. 233-241, 2004.

[12] C. R. Tirapelli, S. R. Ambrosio, F. B. da Costa, and A. M. de Oliveira, "Antispasmodic and relaxant actions of kaurenoic acid (KA) isolated from Viguiera robusta on rat carotid," Brazilian Journal of Pharmaceutical Sciences, vol. 39, supplement 2, article 148, 2003.

[13] M. S. Melis and A. R. Sainati, "Effect of calcium and verapamil on renal function of rats during treatment with stevioside," Journal of Ethnopharmacology, vol. 33, no. 3, pp. 257-262, 1991.

[14] C. N. Lee, K. L. Wong, J. C. Liu, Y. J. Chen, J. T. Cheng, and P. Chan, "Inhibitory effect of stevioside on calcium influx to produce antihypertension," Planta Medica, vol. 67, no. 9, pp. 796-799, 2001.

[15] C. R. Tirapelli, M. D. A. Filho, D. Bonaventura et al., "Pimaradienoic acid inhibits vascular contraction and induces hypotension in normotensive rats," Journal of Pharmacy and Pharmacology, vol. 60, no. 4, pp. 453-459, 2008.

[16] U. V. Hipólito, G. J. Rodrigues, C. N. Lunardi et al., "Mechanisms underlying the vasorelaxant action of the pimarane ent8(14),15-pimaradien-3 $\beta$-ol in the isolated rat aorta," European Journal of Pharmacology, vol. 616, no. 1-3, pp. 183-191, 2009.

[17] S. Müller, C. R. Tirapelli, A. M. de Oliveira, R. Murillo, V. Castro, and I. Merfort, "Studies of ent-kaurane diterpenes from Oyedaea verbesinoides for their inhibitory activity on vascular smooth muscle contraction," Phytochemistry, vol. 63, no. 4, pp. 391-396, 2003.

[18] J. A. Takahashi, H. S. Vieira, M. A. D. Boaventura, J. R. Hanson, P. B. Hitchcock, and A. B. de Oliveira, "Mono and diterpenes from seeds of xylopia sericea," Quimica Nova, vol. 24 , no. 5, pp. 616-618, 2001.

[19] N. C. de Andrade, J. M. Barbosa-Filho, M. S. da Silva, E. V. L. da Cunha, and J. G. S. Maia, "Diterpenes and volatile constituents from the leaves of Xylopia cayennensis," Biochemical Systematics and Ecology, vol. 32, no. 11, pp. 10551058, 2004.

[20] K. Sakata and H. Karaki, "Effects of a novel smooth muscle relaxant, KT-362, on contraction and cytosolic $\mathrm{Ca}^{2+}$ level in the rat aorta," British Journal of Pharmacology, vol. 102, no. 1, pp. 174-178, 1991.

[21] S. Monacada and J. R. Vane, "Pharmacology and endogenous roles of prostaglandins endoperoxydes, throboxane $\mathrm{a}_{2}$ and prostacyclin," Pharmacological Reviews, vol. 30, pp. 293-331, 1997.

[22] P. M. Vanhoutte, C. M. Boulanger, and J. V. Mombouli, "Endothelium-derived relaxing factors and converting enzyme inhibition," American Journal of Cardiology, vol. 76, no. 15 , pp. 3E-12E, 1995.
[23] N. Toda and T. Okamura, "The pharmacology of nitric oxide in the peripheral nervous system of blood vessels," Pharmacological Reviews, vol. 55, no. 2, pp. 271-324, 2003.

[24] H. Kruszyna, J. S. Magyar, L. G. Rochelle, M. A. Russell, R. P. Smith, and D. E. Wilcox, "Spectroscopic studies of nitric oxide (NO) interactions with cobalamins: reaction of $\mathrm{NO}$ with superoxocobalamin(III) likely accounts for cobalamin reversal of the biological effects of NO," Journal of Pharmacology and Experimental Therapeutics, vol. 285, no. 2, pp. 665-671, 1998.

[25] T. A. Bruning, M. G. C. Hendriks, P. C. Chang, E. A. P. Kuypers, and P. A. van Zwieten, "In vivo characterization of vasodilating muscarinic-receptor subtypes in humans," Circulation Research, vol. 74, no. 5, pp. 912-919, 1994.

[26] Y. Sawada, T. Sakamaki, T. Nakamura, K. Sato, Z. Ono, and K. Murata, "Release of nitric oxide in response to acetylcholine is unaltered in spontaneously hypertensive rats," Journal of Hypertension, vol. 12, no. 7, pp. 745-750, 1994.

[27] K. Sato, H. Ninomiya, S. Ohkura, H. Ozaki, and T. Nasu, "Impairment of PAR-2-mediated relaxation system in colonic smooth muscle after intestinal inflammation," British Journal of Pharmacology, vol. 148, no. 2, pp. 200-207, 2006.

[28] J. J. Hwa, L. Ghibaudi, P. Williams, and M. Chatterjee, "Comparison of acetylcholine-dependent relaxation in large and small arteries of rat mesenteric vascular bed," American Journal of Physiology, vol. 266, no. 3, pp. H952-H958, 1994.

[29] H. Shimokawa, H. Yasutake, K. Fujii et al., "The importance of the hyperpolarizing mechanism increases as the vessel size decreases in endothelium-dependent relaxations in rat mesenteric circulation," Journal of Cardiovascular Pharmacology, vol. 28, no. 5, pp. 703-711, 1996.

[30] H. Tomioka, Y. Hattori, M. Fukao et al., "Relaxation in different-sized rat blood vessels mediated by endotheliumderived hyperpolarizing factor: importance of processes mediating precontractions," Journal of Vascular Research, vol. 36, no. 4, pp. 311-320, 1999.

[31] G. Edwards, K. A. Dora, M. J. Gardener, C. J. Garland, and A. H. Weston, " $\mathrm{K}^{+}$is an endothelium-derived hyperpolarizing factor in rat arteries," Nature, vol. 396, no. 6708, pp. 269-272, 1998.

[32] B. Fissithaler, R. Popp, L. Kiss et al., "Cytochrome P450 2C is an EDHF synthase in coronary arteries," Nature, vol. 401, no. 6752, pp. 493-497, 1999.

[33] M. Feletou and P. M. Vanhoutte, "Endothelium-dependent hyperpolarization of canine coronary smooth muscle," British Journal of Pharmacology, vol. 93, no. 3, pp. 515-524, 1988.

[34] T. Nagao and P. M. Vanhoutte, "Hyperpolarization as a mechanism for endothelium-dependent relaxations in the porcine coronary artery," Journal of Physiology, vol. 445, pp. 355-367, 1992.

[35] H. E. Guo-Wei, C. Q. Yang, W. F. Graier, and J. A. N. Yang, "Hyperkalemia alters EDHF-mediated hyperpolarization and relaxation in coronary arteries," American Journal of Physiology, vol. 271, no. 2, pp. H760-H767, 1996.

[36] M. T. Nelson and J. M. Quayle, "Physiological roles and properties of potassium channels in arterial smooth muscle," American Journal of Physiology, vol. 268, no. 4, pp. C799-C822, 1995.

[37] W. B. Campbell, D. Gebremedhin, P. F. Pratt, and D. R. Harder, "Identification of epoxyeicosatrienoic acids as endotheliumderived hyperpolarizing factors," Circulation Research, vol. 78, no. 3, pp. 415-423, 1996.

[38] J. R. McNeill and T. M. Jurgens, "A systematic review of mechanisms by which natural products of plant origin 
evoke vasodilatation," Canadian Journal of Physiology and Pharmacology, vol. 84, no. 8-9, pp. 803-821, 2006.

[39] H. Y. Kim, H. Oh, X. Li, K. W. Cho, D. G. Kang, and H. S. Lee, "Ethanol extract of seeds of Oenothera odorata induces vasorelaxation via endothelium-dependent NO-cGMP signaling through activation of Akt-eNOS-sGC pathway," Journal of Ethnopharmacology, vol. 133, no. 2, pp. 315-323, 2011.

[40] T. Münzel, R. Feil, A. Mülsch, S. M. Lohmann, F. Hofmann, and U. Walter, "Physiology and pathophysiology of vascular signaling controlled by cyclic guanosine 3',5'-cyclic monophosphate-dependent protein kinase," Circulation, vol. 108, no. 18, pp. 2172-2183, 2003.

[41] C. H. Lee, D. Poburko, P. Sahota, J. Sandhu, D. O. Ruehlmann, and C. van Breemen, "The mechanism of phenylephrinemediated $\left[\mathrm{Ca}^{2+}\right]_{i}$ oscillations underlying tonic contraction in the rabbit inferior vena cava," Journal of Physiology, vol. 534, no. 3, pp. 641-650, 2001.

[42] A. P. Somlyo and A. V. Somlyo, "Signal transduction and regulation in smooth muscle," Nature, vol. 372, no. 6503, pp. 231-236, 1994.

[43] P. H. Ratz and K. M. Berg, "2-Aminoethoxydiphenyl borate inhibits KCl-induced vascular smooth muscle contraction," European Journal of Pharmacology, vol. 541, no. 3, pp. 177183, 2006.

[44] P. A. A. Leijten and C. van Breemen, "The effects of caffeine on the noradrenaline-sensitive calcium store in rabbit aorta," Journal of Physiology, vol. 357, pp. 327-339, 1984.

[45] C. R. Tirapelli, S. R. Ambrosio, F. B. da Costa, and A. M. de Oliveira, "Evidence for the mechanisms underlying the effects of pimaradienoic acid isolated from the roots of Viguiera arenaria on rat aorta," Pharmacology, vol. 70, no. 1, pp. 31-38, 2004.

[46] D. F. P. Duarte, A. E. G. Sant'Ana, and J. B. Calixto, "Analysis of the vasorelaxant action of jatrophone in the isolated aorta of the rat: influence of potassium channel blockers," European Journal of Pharmacology, vol. 215, no. 1, pp. 75-81, 1992.

[47] M. J. Mulvany and C. Aalkjaer, "Structure and function of small arteries," Physiological Reviews, vol. 70, no. 4, pp. 921951, 1990. 


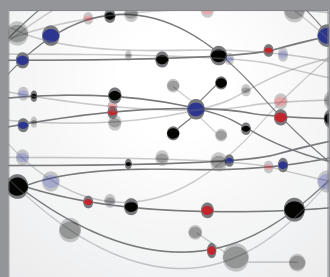

The Scientific World Journal
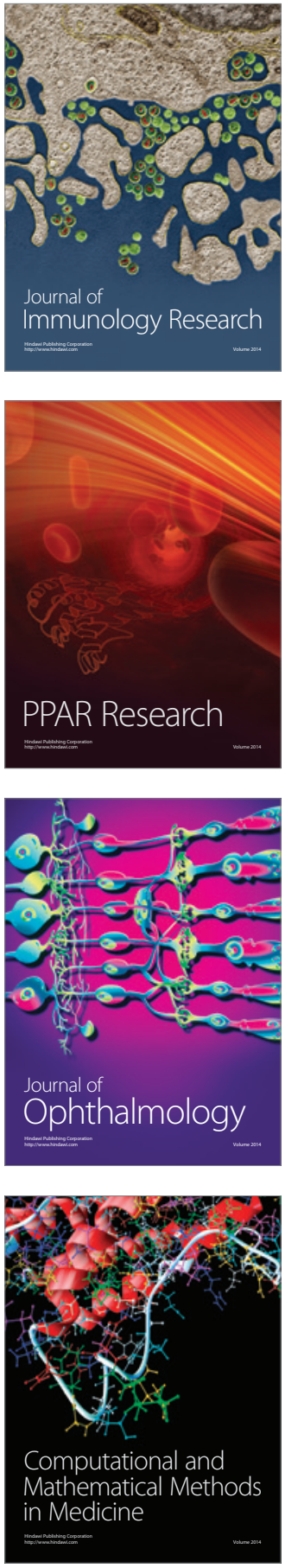

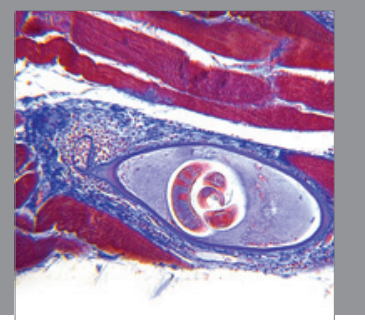

Gastroenterology

Research and Practice
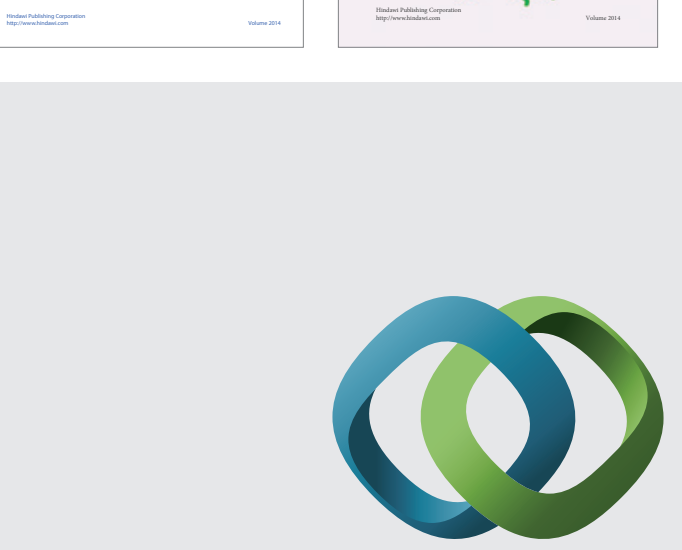

\section{Hindawi}

Submit your manuscripts at

http://www.hindawi.com
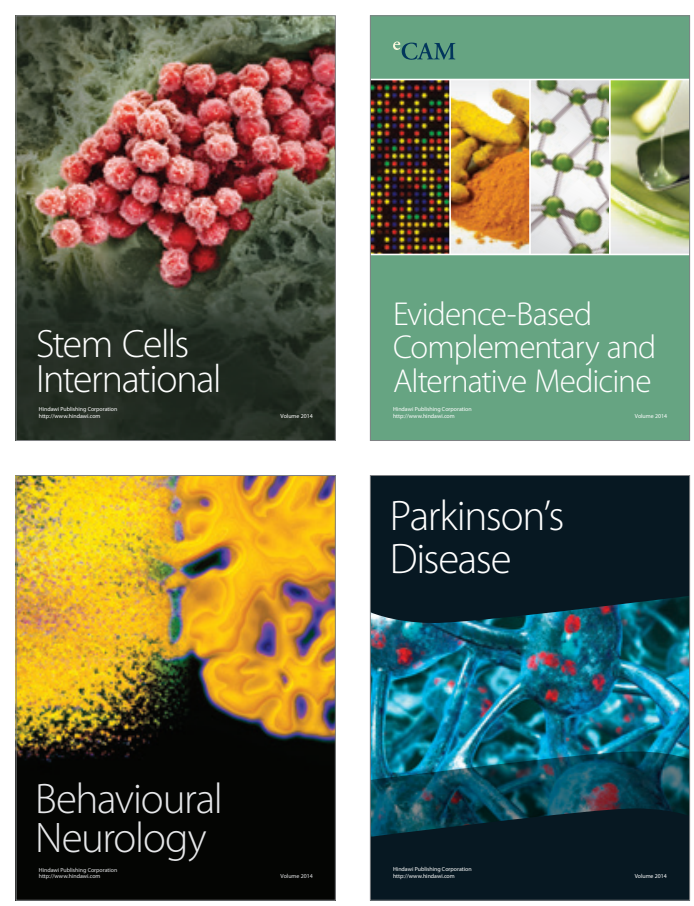

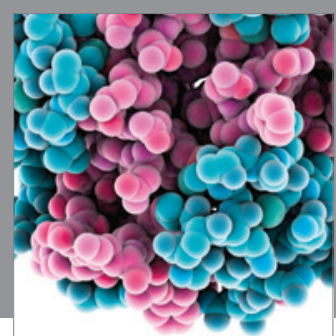

Journal of
Diabetes Research

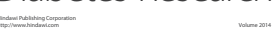

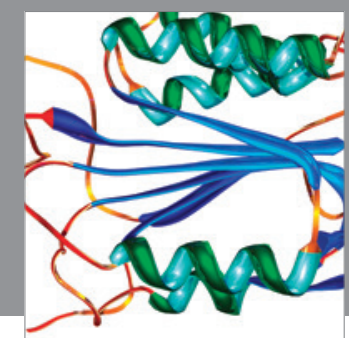

Disease Markers
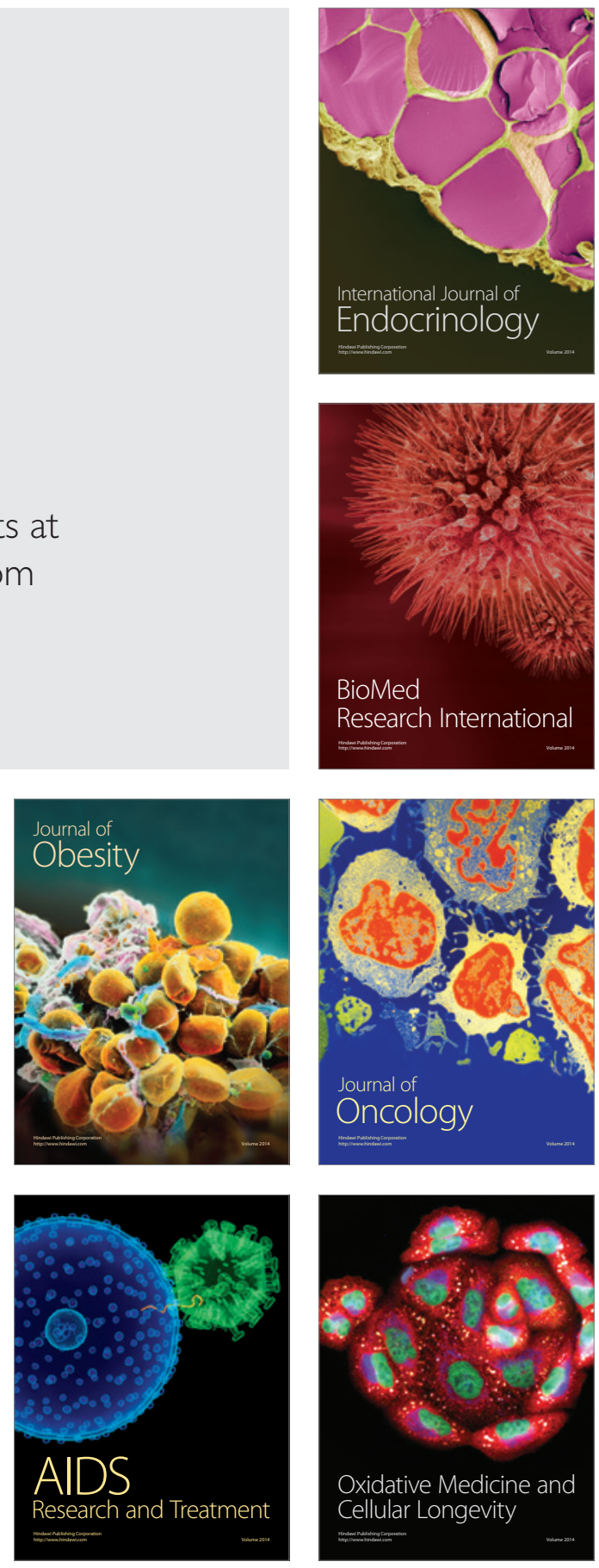